\title{
Meet the flow chemists Prof. Steve Christie and Prof. Shawn Collins
}

\section{Timothy Noël ${ }^{1}$}

Published online: 9 March 2021

(C) Akadémiai Kiadó 2021

\section{Meet The Flow Chemist - Prof. Steve Christie}

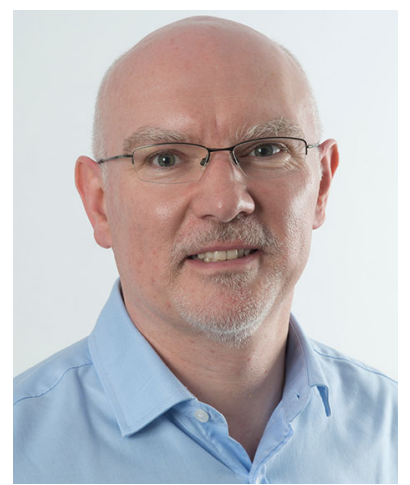

1) When did you start with flow chemistry? Describe the first paper or the first experiments.

We started first with 3D printing of chemical reactors, and quickly figured out the best implementation of this would be flow reactors. In around 2012, an engineer at Loughborough asked me about the chemistry of the additive manufacturing of nylon, and my reply was: "What's additive manufacturing?"! We quickly developed a research topic in using 3D printing and translated it to making flow-type reactors with unique geometries, and using a number of different materials.

\section{Timothy Noël}

t.noel@uva.nl

1 Department of Chemical Engineering and Chemistry, Eindhoven University of Technology, Eindhoven, Netherlands

\begin{tabular}{ll}
\hline $\begin{array}{l}\text { Name } \\
\text { Position }\end{array}$ & $\begin{array}{l}\text { Steve Christie } \\
\text { Professor of Chemical Technologies, } \\
\text { Loughborough University (UK) } \\
\text { E-mail } \\
\text { Homepage }\end{array}$ \\
$\begin{array}{l}\text { s.d.christie@ @ lboro.ac.uk } \\
\text { https:/www.lboro.ac.uk/departments/chemistry/ } \\
\text { staff/academic-research/steve-christie/ }\end{array}$ \\
BSc in Chemistry, University of Strathclyde 1990 \\
PhD in Chemistry, University of Strathclyde \\
(Billy Kerr) 1993 \\
Postdoc, Boston College (Ross Kelly) 1993-1994 \\
Postdoc, University of Southampton \\
(Richard Whitby) 1994-1997 \\
Head of Department, Dept of Chemistry, \\
Loughborough University
\end{tabular}

2) What are the main benefits of flow that convinced you to use and implement this technology in your research?

As outlined above, we came to flow to achieve a goal in 3D printing. It became evident that being able to print "tubing" was novel, but also that just printing tubes was not going to be a sufficient end goal. However, the further opportunities offered by introducing unique geometries, built in analytics, embedded catalysis and the like is both very challenging and highly rewarding.

3) What do you think the future holds for flow chemistry?

For me, it's the confluence of several different technologies that hold the key: flow chemistry, 3D printing with embedded sensors, and data driven applications. If we can build bespoke reactors that have the correct geometries, have built-in analytical capability, and can employ an automated feedback, we can move towards smart reactors that can self-optimise. That will allow chemistry to evolve in a quicker and more robust fashion. 
4) Do you have any relevant tips for newcomers in the field?

Don't be over-awed by a cost to entry. You can achieve a lot with simple syringe pumps and tubing. Once you have the basic understanding of how it works, think how you can add most value. That might be to discover new reactions, or it might be to optimize an older one. But most of all, think outside the box: think what you actually need from your reaction, and don't be constrained by conventional thinking.

\section{My three most relevant papers related to flow chemistry:}

1) $3 \mathrm{D}$ printed microfluidic device with integrated optical sensing for particle analysis

Hampson, Sarah; Rowe, William; Christie, Steven; Platt, Mark. Sensors and Actuators B: Chemical, 2017, 1030. DOI: https://doi.org/10.1016/j.snb.2017.10.041

This paper is a collaboration with analytical colleagues. We designed and built a microfluidic flow device with an integrated optical sensor employing fibre optics, that allowed us to count, size and shape individual particles in real time.
2) 3D printed fluidics with embedded analytic functionality for automated reaction optimisation

Capel, A. J., Wright, A., Harding, M. J., Weaver, G. W., Li, Y., Harris, R. A., Edmondson, S., Goodridge, R. D., Christie, S. D. R. Beilstein J. Org. Chem. 2017, 13, 111. DOI: https:// doi.org/10.3762/bjoc.13.14

Here, we employed the design freedom of 3D printing to design a flow reactor that could be used in tandem with an existing HPLC system. The flow reactor integrated into the HPLC and we performed online reaction monitoring and optimisation of a heterocycle forming reaction.

3) Customisable 3D printed microfluidics for integrated analysis and optimisation

Monaghan, T., Harding, M. J., Harris, R. A., Friel, R. J., Christie, S. D. R. Lab Chip, 2016, 16, 3362 DOI: https://doi. org/10.1039/c6lc00562d

This was the first paper where we were able to show how integration of different technologies can be used to advance flow chemistry. Here, we embedded an optical fibre across a flow channel and monitored a reaction by UV in real time, optimizing it by Design of Experiments. 


\section{Meet The Flow Chemist - Prof. Shawn Collins}

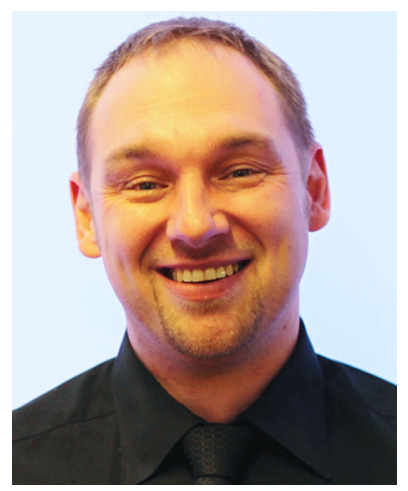

1) When did you start with flow chemistry? Describe the first paper or the first experiments.

We got into flow chemistry around 2010-2011...we had two separate ongoing projects in catalysis that were very different. One of the projects was thermally promoted while the other was photochemical. What was similar was that both of the processes suffered from long reaction times and we recognized how much time was being wasted. Our initial investigations used both homemade experimental set-ups, and commercially available equipment. Once the group understood the basics, we realized that we had scratched only the surface of what we could do with flow.

2) What are the main benefits of flow that convinced you to use and implement this technology in your research?

As I mentioned above, improving reaction times was the first feature that attracted us to flow. However, it wasn't long before a number of other benefits became apparent. Our group's photochemical project involved visible light, but we had long wanted to explore photochemistry at higher energy wavelengths- flow made this possible. We wanted to demonstrate the power of our methods to prepare key compounds on large scales- again flow made this possible, almost trivial really.

3) What do you think the future holds for flow chemistry?

I think that the merger of flow techniques with automation, robotics and AI can change the way we do research in molecular synthesis. The combination allows researchers to push beyond the limits of the round bottom flask. The potential of automation, robotics and AI to rapidly assess reaction outcomes and predict new experiments is already well recognized

\begin{tabular}{ll}
\hline $\begin{array}{l}\text { Name } \\
\text { Position }\end{array}$ & $\begin{array}{l}\text { Shawn Collins } \\
\text { Professor of Chemistry, Université de } \\
\text { Montréal (Canada) }\end{array}$ \\
E-mail & shawn.collins@ umontreal.ca \\
Homepage & https:/collinsudem.wixsite.com/shawn \\
Education & BSc. 1993-1997, Concordia University \\
& PhD 1997-2001, University of Ottawa \\
& (with Prof. Alex Fallis) \\
& PostDoc 2002-2003, University of California \\
at Irvine (with Prof. Larry Overman) \\
2020 NSERC Accelerator Supplement Awardee \\
2014-2020 Co-Director of NSERC CREATE \\
program in Continuous Flow \\
Science2006 Synthesis/Synlett Journal Award 2006 \\
Boehringer Ingelheim Young Investigator Award
\end{tabular}

by the community- but when you add the inherent safety and range of reaction conditions permissible through flow- it means chemists can imagine and explore chemical space further than ever before.

4) Do you have any relevant tips for newcomers in the field?

There are lots of great tips, especially from previous researchers who have been highlighted by "Meet the Flow Chemist". There is obviously lots of literature out there to help beginners. Collaborating with others who have more experience is always a plus. One of the things that I hear so very often is the difficulty in convincing others to try flow... I think my group would say that the "perceived activation barrier" is much higher than the "actual activation barrier". Do not be scared and go for it!

\section{My three most relevant papers related to flow chemistry:}

1. Hernandez-Perez, A. C.; Collins, S. K. A Visible Light Mediated Synthesis of Carbazoles. Angew. Chem., Int. Ed. 2013, 52, 12,696-12,700.

The manuscript described our efforts to use copper-based complexes for photocatalysis, but highlighted how flow chemistry allowed us to improve the reaction times and render the chemistry user-friendly. A later extension of this work in: Hernandez-Perez, A.; Caron, A.; Collins, S. K. Photochemical Synthesis of Complex Carbazoles: Evaluation of Electronic Effects in Both UV- and VisibleLight Methods in Continuous Flow. Chem Eur J. 2015, $16,673-16,678$, is also noteworthy because it compares using visible-light and UV-light to obtain different selectivities, and both processes use flow conditions. 
2. Bédard, A.-C.; Regnier, S.; Collins, S. K. ContinuousFlow Macrocyclization at High Concentrations: Synthesis of Macrocyclic Lipids. Green Chem. 2013, 15, 1962-1966.

The manuscript was one of the first examples of macrocyclization processes in flow.

3. Parisien-Collette, S.; Collins, S. K. exploiting photochemical processes in multi-step continuous flow: Derivatization of the natural product Clausine C ChemPhotoChem 2018, 2, 855-859
The manuscript describes efforts to insert photochemical processes into multistep reaction sequences, and goes as far as linking two photochemical processes that use different wavelengths to build alkaloid structures resembling bioactive natural products.

Publisher's note Springer Nature remains neutral with regard to jurisdictional claims in published maps and institutional affiliations. 